\title{
Method for Cloning Restriction Fragments Containing the Termini of BAC Inserts
}

BioTechniques 28:1012-1018 (May 2000)

\author{
Tammy R. Plyler and \\ C. Eduardo Vallejos \\ University of Florida, \\ Gainesville, FL, USA
}

\begin{abstract}
We have developed a method to isolate the termini of BAC clones. The method is based on the two unique NotI sites located approximately $300 \mathrm{bp}$ on either side of the EcoRI cloning site of the BAC vector $p E C S$ BAC4. Our strategy includes the following steps: (i) generation of Southern blots with $B A C$ clones digested with NotI and a second restriction enzyme; (ii) identification of the termini attached to the NotI/EcoRI fragment of the BAC vector via hybridization with a probe derived from sequences located between one NotI site (left or right arm) and the cloning site; (iii) ligation of the doubly digested BAC clone (NotI and the selected second restriction enzyme) with an equally doubly digested cloning plasmid vector; and (iv) confirmation of the clone as a terminus. This strategy has allowed us to begin the construction of a contig near a common bean gene that controls resistance to a group of potyviruses.
\end{abstract}

\section{INTRODUCTION}

Map-based cloning $(5,10)$ typically requires the construction of a contig around the targeted gene. For the purpose of constructing a physical map of a genome, contigs are normally assembled by a combination of strategies that include fingerprinting and hybridization $(2,11)$. However, a localized approach is selected instead for mapbased cloning $(5,10)$. Construction of the contig around a target gene is initiated first by screening a large insert library (YAC, BAC, PAC, P1 or cosmid) with the marker closest to the target gene. The second and subsequent steps consist of screening the library for additional overlapping clones with subclones of the terminal sequences obtained from the previous clones. The process is continued with the leading termini of the contig.

Several strategies have been used to isolate the termini of large insert clones. These include the Vectorette PCR approach (6); selective PCR amplification with BAC-derived sequences of ligated restriction fragments containing terminal sequences $(4,9)$; thermal asymmetric interlaced PCR (3); and purification of fragments from agarose gels after identification by hybridization, with a linear probe obtained by linear amplification of terminal sequences using a vector-derived primer (12). We have developed a method for cloning restriction fragments of up to $3500 \mathrm{bp}$ and containing terminal sequences of BAC inserts. Our approach makes use of the two unique NotI sites flanking the EcoRI cloning site of the BAC vector pECSBAC4 (1).

The NotI sites are each located approximately $300 \mathrm{bp}$ from the EcoRI cloning site. Our strategy for cloning the termini includes the following steps: (i) generation of Southern blots containing double digests of the BAC clone with NotI and a second restriction enzyme; (ii) hybridization of the Southern blot with a BAC-derived sequence, located between one of the NotI sites (left or right arm) and the cloning site to identify hybridizing fragments larger than $300 \mathrm{bp}$; (iii) ligation of the doubly digested BAC clone (NotI and the selected second restriction enzyme) with an equally doubly digested cloning plasmid vector (pBlueScript ${ }^{\circledR}$; Stratagene, La Jolla, CA, USA); (iv) confirmation of the clone as a terminus of the BAC clone and $(v)$ identification of the contig's termini.

\section{MATERIALS AND METHODS}

\section{BAC Clones}

This BAC library was constructed from the cultivar "Sprite" (8) in the vector pECSBAC4 (1). BAC DNA was extracted according to the alkaline lysis protocol (7). Typically, $10 \mathrm{~mL}$ LB medium containing $12.5 \mu \mathrm{g} / \mathrm{mL}$ chloramphenicol were inoculated, and the culture was grown overnight with constant agitation $(220 \mathrm{rpm})$ at $37^{\circ} \mathrm{C}$. One and one-half milliliter of culture were pelleted in a microcentrifuge for $1 \mathrm{~min}$ at $19800 \times g_{\max }$. The cells were resuspended in $200 \mu \mathrm{L}$ GTE buffer $(50 \mathrm{mM}$ glucose, $25 \mathrm{mM}$ Tris- $\mathrm{HCl}[\mathrm{pH} 8.0]$ and $10 \mathrm{mM}$ EDTA) and lysed at room temperature by the addition of $300 \mu \mathrm{L}$ solution containing $0.2 \mathrm{M} \mathrm{NaOH}$ and $1 \%$ SDS. After being gently mixed, the samples were incubated at room temperature for no more than $5 \mathrm{~min}$. The mixture was neutralized by the addition of $300 \mu \mathrm{L} 5 \mathrm{M}$ potassium acetate $(\mathrm{pH}$ 
5.0) and incubated on ice for $5 \mathrm{~min}$. The sample was clarified by centrifugation at $19800 \times g_{\max }$ for $10 \mathrm{~min}$, and the supernatant was transferred to a new tube. RNA was removed by incubation with $200 \mu \mathrm{g} / \mathrm{mL}$ of freshly boiled RNase A (Sigma, St. Louis, MO, USA) at $37^{\circ} \mathrm{C}$ for $30 \mathrm{~min}$. BAC DNA was further purified by chloroform extraction, and precipitation with one volume of isopropanol. DNA was collected by centrifugation at $15000 \mathrm{rpm}$ for 30 $\mathrm{min}$, and the pellet was washed with $500 \mu \mathrm{L}$ ice-cold $100 \%$ ethanol, dried and resuspended in $30 \mu \mathrm{L} 0.1 \times \mathrm{TE}$ buffer [1 mM Tris- $\mathrm{HCl}(\mathrm{pH} 8.0)$ and $0.1 \mathrm{mM}$ EDTA].

\section{Southern Blots}

Approximately 500 ng DNA from each BAC were digested with NotI in combination with BamHI, BglII, HindIII or PstI. Digested DNAs were electrophoresed for $17 \mathrm{~h}$ in $1 \%$ agarose gels at $1.5 \mathrm{~V} / \mathrm{cm}$. The DNA was transferred overnight to nylon membranes (BIODYNE B ${ }^{\circledR}$; Pall, Port Washington, NY, USA) by downward capillary transfer.

BAC-derived probes were used to identify restriction fragments containing insert termini and the BAC NotI-EcoRI fragment at the $3^{\prime}$ end of the lacZ gene (BAC left arm) or the BAC EcoRI-NotI fragment at the $5^{\prime}$ end of the lac $\mathrm{Z}$ gene (BAC right arm). These probes were made and labeled by PCR amplification (Figure 1A) with the following primers: left forward 5'-CTGGCT TAACTATGCGGCAT-3', left reverse 5'-ACTGGCCGTCGTTTTACAAC-3', right forward 5'-GAGTCGACCTGCAGGCAT-3' and right reverse 5'-GCCGATTCATTAATGCAGCT-3'. The $20-\mu \mathrm{L}$ labeling reac-

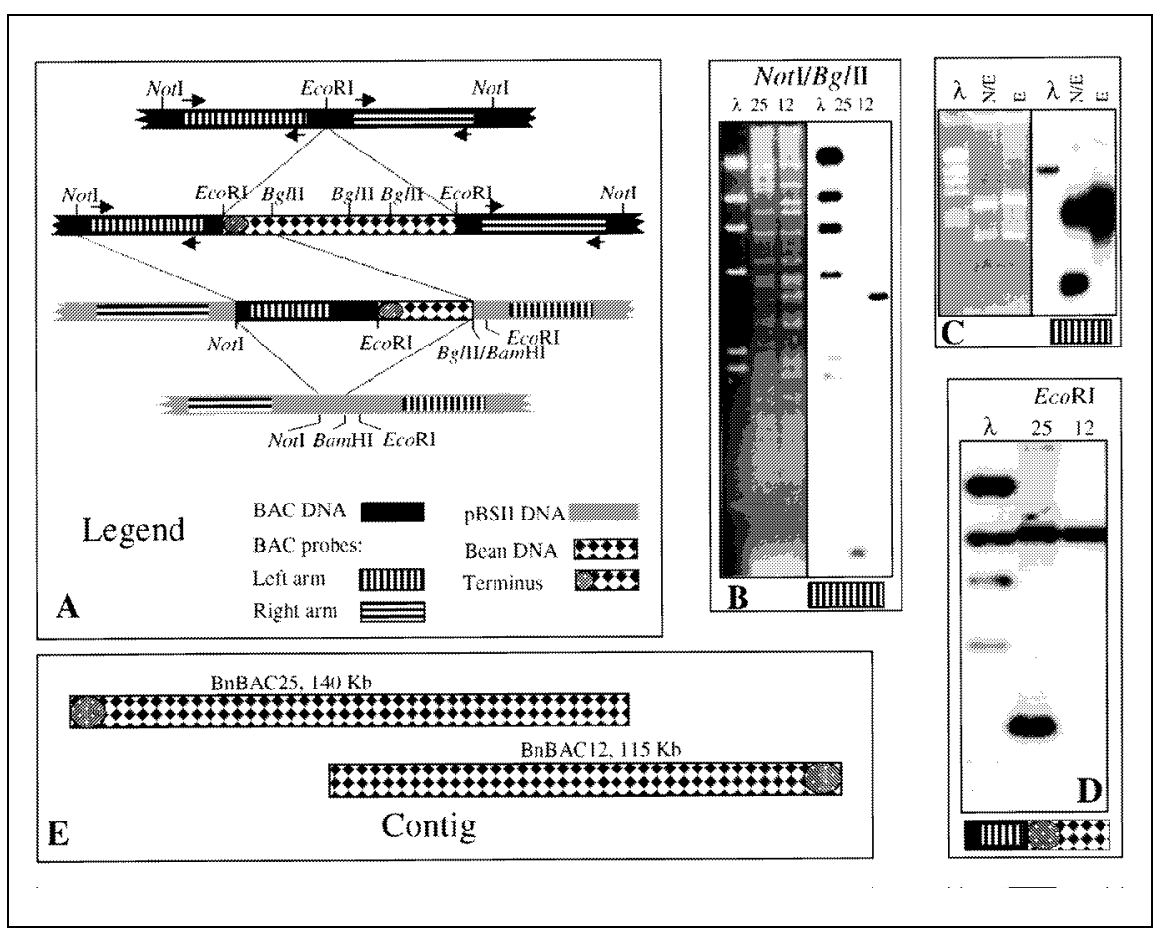

Figure 1. Procedure to clone the termini of large BAC inserts. (A) The top half of the diagram shows the cloning of large inserts into the unique EcoRI site of the BAC vector pECSBAC4, the relative positions of the NotI sites and the position of the left and right arm-specific probes. The bottom half shows the cloning of the NotI/BglII fragment into pBlueScript previously digested with NotI and BamHI. The cloned segment has the $E c o \mathrm{RI} / B g / \mathrm{II}$ terminal sequence of the BAC insert attached to the $N o t \mathrm{I} / E c o$ RI left arm of the BAC vector. (B) The left panel shows the HindIII fragments of $\lambda$ DNA and the NotI/BglII profiles of clones BnBAC25 and BnBAC12. The right panel shows the Southern hybridization profiles obtained with the left arm probe of the BAC vector. (C) The left panel shows the restriction digest profiles (NotI/EcoRI and $E c o \mathrm{RI}$ ) of a terminus cloned in pBlueScript and the right panel shows the hybridization profile with the left arm probe of the BAC vector. (D) Southern hybridization of EcoRI digestion of BnBAC25 and BnBAC12 with the left terminus subclone of BnBAC25. The hybridization of a unique fragment in Bn$\mathrm{BAC} 25$ indicates that the probe contains the leading terminus of the contig. The $9 \mathrm{~kb}$ hybridizing fragment in both lanes is the BAC vector. (E) Representation of the initial contig with two BAC clones. tion included $1 \times$ PCR buffer (Life Technologies, Rockville, MD, USA), 1.5 $\mathrm{mM} \mathrm{MgCl}_{2}, 0.2 \mathrm{mM} \mathrm{dCTP}, 0.2 \mathrm{mM}$ dTTP, 0.2 mM dGTP, $0.071 \mathrm{mM}$ dATP, $0.1 \mu \mathrm{M}$ forward primer, $0.1 \mu \mathrm{M}$ reverse primer, $50 \mu \mathrm{Ci} \alpha$-32P-dATP and $0.5 \mathrm{U}$ Taq DNA polymerase (Life Technologies). The thermocycling conditions were $94^{\circ} \mathrm{C}$ for $2 \mathrm{~min}, 25$ cycles of $94^{\circ} \mathrm{C}$ for $30 \mathrm{~s}, 56^{\circ} \mathrm{C}$ for $30 \mathrm{~s}, 72^{\circ} \mathrm{C}$ for $30 \mathrm{~s}$ and a final extension of $10 \mathrm{~min}$ at $72^{\circ} \mathrm{C}$.

\section{Cloning of Termini}

Restriction fragments smaller than 4 $\mathrm{kb}$ that were detected via Southern hybridizations with BAC right/left armspecific probes were targeted for cloning. Accordingly, $1 \mu \mathrm{g}$ BAC DNA was digested with 50-100 U BamHI, BglII, HindIII or PstI for 3-12 h and precipitated by addition of $1 / 10$ volume $10 \times$ STE buffer $(1 \mathrm{M} \mathrm{NaCl}, 100 \mathrm{mM}$ Tris$\mathrm{HCl}$ [pH 7.8] and 10 mM EDTA), 1 volume of $4 \mathrm{M}$ ammonium acetate and 2.5 volumes $100 \%$ ethanol. After incubation at $-80^{\circ} \mathrm{C}$ for at least $30 \mathrm{~min}$, the DNA was pelleted at $17000 \times g_{\max }$ for $15 \mathrm{~min}$ at $4^{\circ} \mathrm{C}$; the pellet was washed with $70 \%$ ethanol, dried and resuspended in distilled water. The DNA fragments were then digested with 50-100 U NotI for $3-12 \mathrm{~h}$ and precipitated in ethanol as described earlier. Finally, the DNA was resuspended in distilled water at a concentration of about $40 \mathrm{ng} / \mu \mathrm{L}$.

pBlueScript II SK+ was the vector selected for cloning the BAC termini. Ten micrograms of pBlueScript were doubly digested as described previously except that $B g l \mathrm{II}$ was not used because this enzyme and BamHI generate compatible ends. To eliminate undigested plasmid, the doubly digested pBlueScript was loaded into a $0.8 \%$ agarose gel and electrophoresed at 2 $\mathrm{V} / \mathrm{cm}$ for $5 \mathrm{~h}$. The linearized vector was excised from the gel, purified with the Prep-A-Gene ${ }^{\circledR}$ kit (Bio-Rad Laboratories, Hercules, CA, USA) according to the manufacturer's instructions and finally eluted with distilled water.

Ligations were carried out in $10 \mu \mathrm{L}$ volumes and at room temperature for 4-16 $\mathrm{h}$. The reaction mixture contained $1 \times$ ligase buffer, $5 \mathrm{U}$ T4 DNA ligase (both from Life Technologies), 50-200 ng pBlueScript and 200-400 ng BAC DNA. After completion, ligations were 
brought up to $25 \mu \mathrm{L}$ with distilled water and were desalted with Micro Bio-Spin $6^{\circledR}$ microchromatography columns (Bio-Rad Laboratories).

The equivalent of $20 \mathrm{ng}$ vector DNA was used for transformation of electroporation competent XL1-BLUE $E$. coli cells. Cells were pulsed at $2.5 \mathrm{kV}$ in a $0.2-\mathrm{cm}$ cuvette using the $E$. coli pulser transformation apparatus (Bio-Rad Laboratories). Transformed cells were immediately transferred to $1 \mathrm{~mL}$ SOC media (7) and incubated at $37^{\circ} \mathrm{C}$ for 45 min in an orbital shaker at $200 \mathrm{rpm}$. One hundred microliters of culture were plated on agar plates containing SOB media (7), X-Gal, IPTG and 50 $\mu \mathrm{g} / \mathrm{mL}$ ampicillin. Plates were incubated at $37^{\circ} \mathrm{C}$ for $16 \mathrm{~h}$.

\section{Screening of White Colonies}

Each white colony was resuspended in $50 \mu \mathrm{L}$ sterile water and frozen at $-80^{\circ} \mathrm{C}$. Following a quick thaw, the tube was spun at $19800 \times g_{\max }$ for $15 \mathrm{~min}$ at $4^{\circ} \mathrm{C}$, and $2 \mu \mathrm{L}$ supernatant were used for PCR. PCR conditions were the same as listed earlier for labeling the BAC ends, except that $0.2 \mathrm{mM}$ dATP (no radioisotope was included) and 35 cycles of amplification were used instead. Amplifications of insert DNA were carried out with pBlueScript-derived primers, T3 and KS17. PCR amplification products were resolved by agarose gel electrophoresis.

\section{RESULTS}

Although we constructed a contig with several BAC clones, we describe here only those results obtained with BnBAC12 and BnBAC25, the first two BAC clones selected from the $P$. vulgaris BAC library.

\section{Identification of Fragments Containing BAC Insert Termini}

Southern hybridizations containing double digests (Not $\mathrm{I} / \mathrm{second}$ restriction enzyme) of BAC clones with the BAC left arm probe revealed the presence of single fragments that varied in size from 400-9000 bp. The Southern blot in Figure 1B shows a $0.4-\mathrm{kb}$ Not I/ BglII fragment for $\mathrm{BnBAC} 25$, and a $3-\mathrm{kb}$ fragment for BnBAC12. In contrast, similar blots hybridized with the BAC right arm probe displayed an approximate 300-bp fragment with all the restriction enzymes used in our analysis, with the exception of $B g l I I$ (Figure 2). These results were obtained because of the presence of BamHI, HindIII and PstI sites between the EcoRI cloning site and the NotI site on the right arm of the BAC vector.

The presence of multiple restriction sites in the right arm of the BAC vector presented a problem when the NotI/ $B g l$ II restriction fragment containing the terminus was too large (greater than $4 \mathrm{~kb}$ ) to be cloned in pBlueScript. This problem was overcome by obtaining a complete digestion of the BAC DNA with NotI and a partial digestion with the second restriction enzyme (BamHI, HindIII or PstI). Figure 2 shows the results of the hybridization of four BAC clones with the BAC right arm probe. Complete NotI/BglII digestion of Bn$\mathrm{BAC} 12$ revealed the presence of a $9-\mathrm{kb}$ fragment containing the terminus. Although a fragment of this size can be cloned in pBlueScript, the efficiency is quite low. Complete digests of NotI/ second restriction enzyme revealed the presence of a 300-bp fragment that does not contain insert DNA. However, partial digestions with the second restriction enzyme contained the terminus. For instance, BnBAC12 has a 2.5$\mathrm{kb} N o t \mathrm{I} /$ HindIII and a $3-\mathrm{kb}$ Not $\mathrm{I} / P s t \mathrm{I}$ fragment (Figure 2).

\section{Cloning BAC Insert Termini}

Two approaches were tested for cloning the termini. In the first approach, we ligated to the plasmid vector restriction fragments of the selected size range isolated from agarose gels. This procedure was discontinued because it required large amounts of BAC DNA and offered low yields. In the second approach, we ligated the doubly digested BAC DNA to the equally doubly digested plasmid vector. This procedure yielded many white colonies.

White colonies were subjected to a two-tier screening procedure: $(i)$ insertsize selection and (ii) restriction and Southern analyses. The double screen was performed because ligations between the plasmid vector and double digests of the entire BAC clone can yield clones of internal restriction fragments, in addition to the terminal fragments. All Not $\mathrm{I} / \mathrm{secondary}$ restriction enzyme fragments are not necessarily from a terminus because many BAC inserts contain a single internal NotI site. Another possibility is the ligation of restriction fragments that are cut at both ends with the second restriction enzyme to a small fraction of contaminating singly digested plasmid.

The first screening detected inserts of different sizes. Only clones with inserts of the expected size were subjected to the second round of selection. EcoRI and $N o t \mathrm{I} / E c o R I$ digestions of plasmid DNA from candidate clones were separated by $1 \%$ agarose gel electrophoresis in minigels (Figure 1C, left panel), and the Southern blots of these gels were used for hybridizations with the radiolabeled BAC left or right arm probe (Figure $1 \mathrm{C}$, right panel). Positive clones

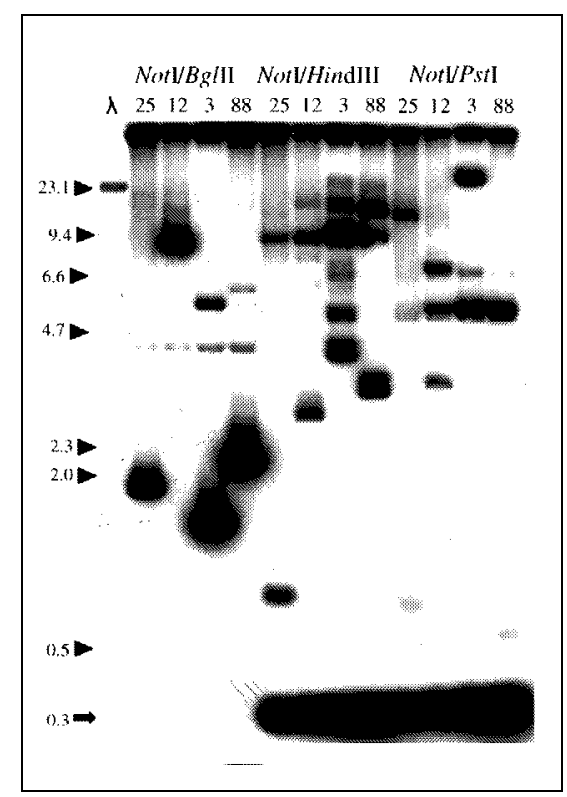

Figure 2. Southern analysis with the right arm probe. Southern blot showing the hybridization results of the $\mathrm{BAC}$ right arm probe to four BAC clones (BnBAC25, 12, 3 and 88). Complete digestions with a combination of NotI and BglII show restriction fragments varying in size between 1 and $9 \mathrm{~kb}$. In contrast, complete digestion with NotI followed by a partial digestion with HindIII or PstI showed a band of approximately $300 \mathrm{bp}$ in all four clones. This band corresponds to a HindIII-NotI or PstI-NotI BAC sequence to the right of the EcoRI cloning site. The corresponding HindIII and Pst I sites in the BAC vector are within 50 bp from the cloning site. Larger hybridizing fragments were the result of partial digestions. 
were identified by their expected restriction and hybridization patterns. The EcoRI digestion of a positive clone was expected to release a minimum of two restriction fragments, which result from cuts at the EcoRI cloning site of the $\mathrm{BAC}$ vector and at the EcoRI site of pBlueScript. Additional fragments can be observed if the insert contains internal EcoRI sites. The addition of NotI to the EcoRI digestion of positive clones is expected to yield a minimum of three fragments: the approximate 2.9-kb Not $\mathrm{I} /$ EcoRI fragment of pBlueScript, the 300 bp NotI/EcoRI fragment corresponding to the arm of the BAC vector and the EcoRI fragment representing the terminus of the BAC clone. Furthermore, hybridization of positive clones with the BAC left or right arm should reveal a single fragment that corresponds to the fragment containing the pBlueScript vector and the left or right arm of the BAC vector in the EcoRI lane, and two fragments in the Not $\mathrm{I} / E c o$ RI lane, one corresponding to the fragment containing the pBlueScript vector, and the other to the 300-bp NotI/EcoRI fragment representing the left or right arm of the $\mathrm{BAC}$ vector (Figure 1C). The pBlueScript vector hybridizes to both the BAC left and right arm probes because these are derived from the lac $\mathrm{Z}$ sequence found in pBlueScript and BAC vectors.

\section{Identification of the Leading Termini}

Clones that passed the two-tier screening were tested further to identify the ones at the leading ends of the contigs. Here, we present the analysis for two BAC clones (BnBAC25 and BnBAC12). These clones were selected from the library with the same probe. A comparison of the restriction patterns of these clones (Figure 1B, left panel) shows that they share a number of re- striction fragments and indicates that they overlap. To start the construction of the contig, we needed to identify the non-overlapping termini. For this purpose, we used a single clone from each terminus as a hybridization probe for Southern blots of EcoRI digestion of the BAC clones. The rationale for using $E c o$ RI was that this enzyme would release the most distal fragments of the BAC insert and separate from any BAC sequence. A terminus at the overlapping end of the BAC clone should hybridize to itself and to a fragment from the overlapping BAC clone. In contrast, the leading terminus in the contig should only hybridize to the BAC clone from which it originated. This is illustrated in Figure 1D where one of the termini of BnBAC25 hybridizes to a fragment from the same clone, but not to any fragments from BnBAC12. The 9-kb fragment that hybridized on both lanes is the BAC vector. It shows a 
hybridization signal because the pBlueScript insert of the terminal clone contains the 300-bp NotI/EcoRI fragment of the BAC vector. Such results have allowed us to determine the relative position and orientation of the BAC clones in the contig (Figure 1E).

\section{DISCUSSION}

Southern analysis for the detection of $\mathrm{BAC}$ insert terminal sequences attached to the 300-bp NotI/EcoRI left or right arm of the BAC vector proved to be an effective procedure that led to the efficient cloning of BAC insert terminal sequences. This procedure can be adapted for other BAC vectors that, like pECSBAC4, were derived from pBeloBAC11 and have similar restriction maps near the cloning site. There is no difference between pECSBAC4 and pBeloBAC11 in this region. Analysis of the fragment sizes obtained with different restriction enzymes, used simultaneously with NotI, revealed the relative positions of restriction sites near the EcoRI terminal site. This information can be used to obtain a restriction map of the terminus and for cloning more proximal restriction fragments, if the need arises, when the smallest, most distal fragment proves to be repetitive DNA and one would like to clone adjacent fragments that may contain single-copy sequences. We have also demonstrated that partial digestions with the secondary restriction enzyme are also effective even when a site for the second restriction enzyme is present in the 300-bp NotI/EcoRI fragment of the BAC vector.

This procedure will still be useful when analyzing BAC libraries of species that may have a higher frequency of NotI sites than most species. In such cases, clonable NotI restriction fragments (less than $4 \mathrm{~kb}$ ) that contain the terminus and the adjacent BAC sequence could be recognized by Southern hybridization if a NotI digest of the BAC DNA is included along with the BAC DNA double digests (Not I/secondary restriction enzyme).

The introduction of BigDye ${ }^{\mathrm{TM}}$ sequencing kits (PE Biosystems, Foster City, CA, USA) has facilitated the sequencing of termini using $\mathrm{BAC}$ derived primers, and we have obtained some sequences directly from BAC clones. Each sequencing reaction normally yields a sequence of a few hundred bases. This is a useful and time-saving approach, particularly when the terminus contains single-copy sequences. However, sequencing the termini of BAC inserts can be a slow process when the termini contain highly repetitive DNA and especially when nested repeats are encountered. This problem can be overcome by subcloning a relatively large (approximately 3-4 kb) restriction fragment containing the termini as described here. These subclones can be used to detect single-copy sequences (by either hybridization or sequencing) that may be present at the proximal side. Furthermore, sequence information of the proximal side can be used to design primers for sequencing adjacent internal fragments. Thermal asymmetric interlaced PCR (3) has also been used by our laboratory (Astua-Monge and Vallejos, unpublished results). Typically, this technique yields fragments between 1 and $2 \mathrm{~kb}$, and the number of amplified fragments tends to increase when repetitive DNA sequences are present in the terminus. The procedure described here is offered as an additional tool and is not intended to replace procedures described previously.

\section{ACKNOWLEDGMENTS}

We thank Drs. L.C. Hannah and K. Cline for reviewing this manuscript and offering many valuable suggestions. Blots of the BAC library were obtained from Dr. David Frisch at the Clemson University Genome Center. We also thank Dr. Sally Mackenzie from Purdue University for providing the BAC clones. This work was funded in part by USDA grant no. 97121514. Florida Agricultural Experiment Station Publication No. R-07066.

\section{REFERENCES}

1.Frijters, A.C.J., Z. Zhang, M. van Damme, G.-L. Wang, P.C. Ronald and R.W. Michelmore. 1997. Construction of a bacterial artificial chromosome library containing large EcoRI and HindIII genomic fragments of lettuce. Theor. Appl. Genet. 94:390-399.
2.Hong, G. 1997. A rapid and accurate strategy for rice contig map construction by combination of fingerprinting and hybridization. Plant Mol. Biol. 35:129-133.

3.Liu, Y.-G. and R.F. Whittier. 1995. Thermal asymmetric interlaced PCR: automatable amplification and sequencing of insert end fragments from P1 and YAC clones for chromosome walking. Genomics 25:674-681.

4.Marek, L.F. and R.C. Shoemaker. 1997. BAC contig development by fingerprint analysis in soybean. Genome 40:420-427.

5.Nakamura, S., S. Asakawa, N. Ohmido, K. Fukui, N. Shimizu and S. Kawasaki. 1997. Construction of an 800-kb contig in the nearcentromeric region of the rice blast resistance gene $P i-t a^{2}$ using a highly representative rice BAC library. Mol. Gen. Genet. 254:611-620.

6.Riley, J., R. Butler, D. Ogilvie, R. Finniear, D. Jenner, S. Powell, R. Anand, J.C. Smith and A.F. Markham. 1990. A novel, rapid method for the isolation of terminal sequences from yeast artificial chromosome (YAC) libraries. Nucleic Acids Res. 18:2887-2890.

7.Sambrook, J., E.F. Fritsch and T. Maniatis. 1989. Molecular Cloning: A Laboratory Manual, 2nd ed. CSH Laboratory Press, Cold Spring Harbor, NY.

8.vanHouten, W. and S.A. Mackenzie. 1999. Construction and characterization of a common bean bacterial artificial chromosome library. Plant Mol. Biol. 40:977-983.

9. Woo, S., J. Jiang, B. Gill, A. Paterson and R. Wing. 1994. Construction and characterization of a bacterial artificial chromosome library of Sorghum bicolor. Nucleic Acids Res. 22:4922-4931.

10.Yang, D., A. Sanchez, G.S. Khush, Y. Zhu and N. Huang. 1998. Construction of a BAC contig containing the $\mathrm{Xa} 5$ locus in rice. Theor. Appl. Genet. 97:1120-1124.

11.Zhang, H.-B, and R.A. Wing. 1997. Physical mapping of the rice genome with BACs. Plant Mol. Biol. 35:115-127.

12.Zhu, H., S. Choi, A.K. Johnston, R.A. Wing and R.A. Dean. 1997. A large-insert (130 $\mathrm{kbp}$ ) bacterial artificial chromosome library of the rice blast fungus Magnaporthe grisea: genome analysis, contig assembly, and gene cloning. Fungal Genet. Biol. 21:337-347.

Received 20 August 1999; accepted 8 December 1999.

Address correspondence to:

Dr. C. Eduardo Vallejos

1143 Fifield Hall

Department of Horticultural

Sciences and

Plant Molecular \& Cellular

Biology Graduate Program

University of Florida

Gainesville, FL 32611-0690, USA

Internet:vallejos@ufl.edu 